\title{
A National Research Strategy to Reduce Firearm-Related Injury and Death: Recommendations from the Health Policy Research Subcommittee of the Society of General Internal Medicine (SGIM)
}

\author{
Rhea E. Powell, M.D., M.P.H. ${ }^{7}$ and Chana A. Sacks, M.D., M.P.H \\ 'Division of Internal Medicine, Department of Medicine, Thomas Jefferson University, Philadelphia, PA, USA; ${ }^{2}$ Division of General Internal Medicine \\ and Mongan Institute, Department of Medicine, Massachusetts General Hospital, Harvard Medical School, Boston, MA, USA.
}

\begin{abstract}
Injury due to firearms is a serious health issue in the USA, leading to nearly 40,000 deaths annually and many more non-fatal injuries. Despite the significant impact on morbidity and mortality, relatively little research funding is dedicated to understanding the impact of firearm-related injury and to developing strategies to mitigate harm. In part, research has been stymied by decades-old language in federal legislation that was interpreted as prohibiting federal funding for firearm injury-related research. This paper, prepared by members of the Society of General Internal Medicine (SGIM), calls for support for research that seeks to understand the nature of firearm-related injury and resources to develop effective approaches to prevent it. We outline recommendations to develop evidence to inform policymakers and the medical and public health communities. These recommendations include (1) development of a shared national research agenda to address firearm-related injury and death; (2) allocation of federal funds specifically for research related to firearm injury; (3) support for the career development of researchers studying firearm-related injury; and (4) facilitating access to comprehensive data sources needed for developing evidence.
\end{abstract}

KEY WORDS: research; firearm injury; health policy.

J Gen Intern Med 35(7):2182-5

DOI: $10.1007 / \mathrm{s} 11606-020-05850-\mathrm{x}$

(c) Society of General Internal Medicine 2020

\section{INTRODUCTION}

Injury and death due to firearms are a serious and pressing public health issue. Across the USA in 2017, there were 39,773 deaths due to firearm-related injuries ${ }^{1}$ and many more nonfatal injuries, although nonfatal injury estimates are imprecise. Injuries and deaths due to firearms result from different types of violence, including suicide, interpersonal violence and assault, unintentional injuries, and mass shootings. Firearm-related violence has obvious direct impacts on the individuals injured and families of those who died, but it also

Received March 20, 2020

Accepted April 8, 2020

Published online May 14, 2020 has far-reaching societal impacts including community trauma, adverse childhood events, and health system costs. Policymakers, public health experts, and the medical community lack a comprehensive understanding of the causes and effects of firearm injury, which limits their ability to develop and implement interventions and policies that might reduce harm due to firearms. Knowledge is limited in large part due to years of restrictions on firearm-related research, resulting in too few researchers with relevant experience and expertise.

\section{IMPEDIMENTS TO FEDERAL FUNDING FOR RESEARCH}

Lack of funding for firearm-related research has been a significant limitation on the development of the field. The restricted funding for research related to firearm violence originated with a 1996 federal appropriations bill that included language stating that "none of the funds made available for injury prevention and control at the Centers for Disease Control and Prevention (CDC) may be used to advocate or promote gun control."2 This provision, commonly known as the Dickey Amendment, followed on the heels of an emerging body of research demonstrating the increased risk for both suicide and homicide associated with access to firearms. ${ }^{3,4}$ The effort to stymie federal funding for such research was widely considered to be the result of lobbying efforts by the National Rifle Association (NRA). ${ }^{5}$ Although the language in the amendment did not explicitly prohibit research related to firearms, the bill had a chilling effect on federal funding for firearm injury-related research. The language continued to be included annually in federal appropriations legislation, and the language was extended in 2012 to explicitly include the National Institutes of Health (NIH). ${ }^{6}$

The Dickey Amendment language, and the subsequent freeze in funding for research related to firearm violence, resulted in decades of substantial underfunding for such work compared with other causes of morbidity and mortality. A 2017 study showed that funding for research related to firearm violence was $1.6 \%$ of the level predicted by comparisons with other causes of morbidity and mortality. ${ }^{7}$ Between 1998 and 2012, the relative number of publications related to firearm 
violence steadily declined, ${ }^{8}$ with few active career researchers with expertise in firearm-related injury research. ${ }^{8}$

Although the language prohibiting federal funding for research that could be used to "advocate or promote gun control" has continued to be included in annual appropriation legislation, recent developments indicate more support for research related to firearm injury. A report accompanying a 2018 appropriations bill added language to clarify that "while appropriations language prohibits the $\mathrm{CDC}$ and other agencies from using appropriated funding to advocate or promote gun control, the Secretary of Health and Human Services has stated the CDC has the authority to conduct research on the causes of gun violence." ${ }^{5}$ In 2019, for the first time since the passage of the Dickey Amendment language, legislation was enacted that allocates funding to the CDC and NIH (\$25 million total) specifically for firearm-related injury research.

\section{EFFORTS TO MOVE FIREARM INJURY-RELATED RE- SEARCH FORWARD}

Although federal support for research related to firearm violence has been limited, experts in the medical and public health communities continue to call out the need to address firearm violence in the USA. Medical and public health professionals have convened experts in a range of settings to identify research priorities. In 2013, the CDC and CDCFoundation charged the Institute of Medicine (now the National Academy of Medicine) and National Research Council to convene experts to develop a research agenda on the public health impacts of firearm violence. ${ }^{9}$ The committee outlined a research program that would provide actionable evidence within 5 years. The proposed agenda focused on developing research in five key areas: characteristics of firearm violence; risks and protective factors; interventions and strategies; firearm safety technology; and the influence of video games and other media. Although the 5-year time frame targeted by the report has passed, with funding limited to non-federal sources, many of these research questions remain unanswered. Medical and public health professionals continue to voice a growing consensus about the need for robust evidence on firearm violence. Notable examples include the American College of Emergency Physicians research agenda, ${ }^{10}$ which focuses on questions relevant to emergency medicine, and the Firearm Safety Among Children and Teens (FACTS) consortium agen$\mathrm{da},{ }^{11}$ a pediatric-specific research agenda for firearm injury that resulted from a consortium funded by the National Institute for Child Health and Human Development.

In addition to outlining specific and pressing research questions related to firearm violence, consensus statements from numerous medical and public health organizations highlight that research is an essential component of the public health approach and that research funding must match the burden of disease. ${ }^{12-14}$ Despite the lack of research support, health care providers and health systems strive to evaluate and address firearm violence. ${ }^{15}$ Non-profit organizations such as the American Foundation for Firearm Injury Reduction in Medicine (AFFIRM), comprising health professionals and researchers, have emerged to raise funds and support efforts to understand and mitigate firearm violence through research. ${ }^{16}$ Kaiser Permanente recently committed \$2 million to research firearm injury prevention; Massachusetts General Hospital and Harvard Medical School have allocated \$1.4 million. ${ }^{17,}{ }^{18}$ Although foundation and philanthropic support are important steps, demonstrating the health care community's increasing engagement in this field, federal support and a national strategy for research to address firearm-related injury are urgently needed.

\section{RECOMMENDATIONS FROM THE SOCIETY OF GENERAL INTERNAL MEDICINE}

The Society of General Internal Medicine (SGIM) is a national medical society of general internal medicine physicians across the USA. SGIM members provide primary and hospital-based clinical care; teach medical students, residents, and fellows; and conduct research that improves care, prevention, and treatment for patients. SGIM members have been among those developing the evidence base related to firearm violence ${ }^{19,20}$ and providing a vision for the role of the medical community in addressing firearm-related violence. ${ }^{21-23}$

This paper, prepared with the support of SGIM's Health Policy Committee Research Subcommittee, calls for funding and support for research efforts to understand the factors that cause firearm injury and approaches to reduce injury and death. We outline a set of recommendations to develop a national research portfolio that can inform health care, public health efforts, and policy related to firearm violence. Specifically, we recommend (1) defining a national research agenda to address firearm-related injury and death; (2) allocation of federal funds specifically for research related to firearmrelated injury; (3) support for the careers of firearm injury researchers; and (4) access to the comprehensive data resources needed to develop this evidence base.

\section{Define a National Research Agenda to Address Firearm-Related Injury and Death}

We recommend building on prior and ongoing work to define a national agenda for high-priority research questions that can inform public health and policy decision making and improve health outcomes related to firearms. An updated national research agenda can build on the work of multiple disciplines within medicine and allied public health and criminal justice fields. The national research agenda should incorporate multiple research methodologies to allow for the development of a robust understanding of the interplay of individual, community, and policy-level factors that impact firearm injury and 
violence. The research agenda should include the range of work needed to understand the causes and impacts of firearm injury, as well as the interventions and policies to improve firearm-related health outcomes. The agenda should also include research to support the development of curricula to educate and empower clinicians caring for communities impacted by firearm-related violence. Primary care providers, for example, routinely care for those at increased risk of intentional or unintentional injuries, ${ }^{24}$ yet, standardized education in this area across undergraduate and graduate medical education is lacking. ${ }^{25}$ Such work necessitates a cadre of researchers and educators with the skills, expertise, and support to enact the agenda.

\section{Allocate Federal Funding Specifically for Research Related to Firearm Violence}

Although the recent allocation of $\$ 25$ million to $\mathrm{CDC}$ and $\mathrm{NIH}$ for firearm-related injury research is an important start, additional and sustained funding is needed to address pressing research questions related to firearm violence. Such targeted funding must be provided at a level commensurate with health issues of comparable impact. Funding should support research on the range of priority questions including the causes and impacts of firearm violence as well as the effectiveness of interventions to reduce harm due to firearms. Dissemination of findings will also be essential to ensure a rigorous research base that can be communicated to stakeholders. In addition, the Dickey Amendment language that restricts funding for research that could be used to "advocate or promote gun control" should be dropped, and future appropriations bills should exclude any language that might be interpreted as placing restrictions on research related to firearm injury.

\section{Support the Work and Career Development of Researchers Studying Firearm-Related Injury}

Despite the lack of federal funding, dedicated researchers within academic medicine and public health have provided important insights into understanding firearm-related injury and death. Some researchers have been able to identify non-federal sources of support for research, including foundation and state funding. To build a community of experts who can address priority questions on a national scale, investigators will require supported time, mentorship, and formal training mechanisms such as institutional training grants and career development grants. Without the availability of traditional career development awards, junior investigators have been discouraged from building a career in this area of inquiry. ${ }^{26}$ Support for junior investigators will be particularly important to develop the future of this field. In order to allow researchers to share findings, mechanisms to support the dissemination of evidence will be needed. Additionally, this work will necessitate multidisciplinary partnerships within medicine and with partners in public health, and criminal justice research, as well as collaborations with patient, family, and caregiver communities that represent the diverse groups impacted by firearm-related violence.

\section{Access to Comprehensive Data Needed for Creating an Evidence Base}

Rigorous research requires reliable and accessible data sources. Current studies of firearm injury and death use a combination of data sources to provide estimates of the impact of firearm violence. Data on fatal injuries are collected from the National Vital Statistics System, a product of the CDC's National Center for Health Statistics. Reports of nonfatal firearm injuries cite the National Electronic Injury Surveillance System which includes data from a sample of 66 emergency departments. ${ }^{27}$ Estimates of nonfatal injury, however, are imprecise, and in 2019, the CDC limited the availability of these nonfatal injury data due to the imprecision. The National Violent Death Reporting System compiles state-level reports from multiple sources, including law enforcement, medical examiners and coroners, toxicology, and death certificates, and as of 2018 , has been collecting data from all 50 states, Puerto Rico, and the District of Columbia. ${ }^{28}$ There is limited data on firearm ownership and limited outcome data on nonfatal injuries. A national registry of firearm violence, inclusive of both fatal and nonfatal firearm injuries and publicly available to investigators, has been posited as one solution to improve understanding of firearm violence. ${ }^{29,}{ }^{30}$ In the meantime, enhancing access to existing data as well as developing creative linkages across various data sources should be a priority.

\section{CONCLUSION}

Firearm-related injury is an urgent health issue, causing mortality and morbidity for tens of thousands of Americans annually, with far-reaching implications for community safety and health care systems. A rigorously researched and comprehensive body of evidence is foundational to inform decisions of policymakers and those designing public health and medical interventions. The recommendations outlined here by SGIM are key steps to support the research needed to create this body of evidence, reduce harm from firearms, and improve health.

Acknowledgments: The authors would like to acknowledge the SGIM Health Policy Research Subcommittee for their support of this effort as well as Nancy L. Keating, M.D., M.P.H., Michael A. Fischer, M.D., M.S., and Lyle B. Dennis, M.A. for their helpful comments on earlier drafts of this manuscript.

The SGIM Council has reviewed this manuscript and supports the statements and recommendations.

Corresponding Author: Rhea E. Powell, M.D., M.P.H.; Division of Internal Medicine, Department of Medicine Thomas Jefferson University, Philadelphia, PA, USA (e-mail: rhea.powell@jefferson.edu).

\section{Compliance with Ethical Standards:}

Conflict of Interest: The authors declare that they do not have a conflict of interest. 


\section{REFERENCES}

1. Centers for Disease Control and Prevention, National Center for Health Statistics [Internet]. [cited 2019 Aug 27]; Available from: http://wonder. cdc.gov/ucd-icd10.html

2. Omnibus Consolidated Appropriations Act, 1997 [Internet]. 1996. Available from: https://www.govinfo.gov/content/pkg/PLAW-104publ208/ pdf/PLAW-104publ208.pdf

3. Kellermann AL, Rivara FP, Somes G, et al. Suicide in the home in relation to gun ownership. N Engl J Med 1992;327(7):467-72.

4. Kellermann AL, Rivara FP, Rushforth NB, et al. Gun ownership as a risk factor for homicide in the home. N Engl J Med 1993;329(15):108491

5. Rostron A. The Dickey Amendment on Federal Funding for Research on Gun Violence: A Legal Dissection. Am J Public Health 2018;108(7):865-7.

6. Consolidated Appropriations Act, 2012 [Internet]. 2011. Available from: https://www.govinfo.gov/content/pkg/PLAW-112publ74/pdf/PLAW112publ74.pdf

7. Stark DE, Shah NH. Funding and Publication of Research on Gun Violence and Other Leading Causes of Death. JAMA 2017;317(1):84-5.

8. Alcorn T. Trends in Research Publications About Gun Violence in the United States, 1960 to 2014. JAMA Intern Med 2017;177(1):124-6.

9. IOM (Institute of Medicine) and NRC (National Research Council), editor. Priorities for research to reduce the threat of firearm-related violence. Washington, DC: The National Academies Press; 2013.

10. Ranney ML, Fletcher J, Alter $\mathbf{H}$, et al. A Consensus-Driven Agenda for Emergency Medicine Firearm Injury Prevention Research. Ann Emerg Med 2017;69(2):227-40.

11. Cunningham RM, Carter PM, Ranney ML, et al. Prevention of Firearm Injuries Among Children and Adolescents: Consensus-Driven Research Agenda from the Firearm Safety Among Children and Teens (FACTS) Consortium. JAMA Pediatr 2019; Available from: https://doi.org/10. 1001/jamapediatrics.2019.1494

12. Bulger EM, Kuhls DA, Campbell BT, et al. Proceedings from the Medical Summit on Firearm Injury Prevention: A Public Health Approach to Reduce Death and Disability in the US. J Am Coll Surg 2019; Available from: https://doi.org/10.1016/j.jamcollsurg.2019.05.018

13. Branas CC, Flescher A, Formica MK, et al. Academic Public Health and the Firearm Crisis: An Agenda for Action. Am J Public Health 2017;107(3):365-7.

14. Weinberger SE, Hoyt DB, Lawrence HC 3rd, et al. Firearm-related injury and death in the United States: a call to action from 8 health professional organizations and the American Bar Association. Ann Intern Med 2015;162(7):513-6.

15. National Academies of Sciences, Engineering, and Medicine. Health systems interventions to prevent firearm injuries and death: Proceedings of a workshop [Internet]. Washington, DC: The National Academies Press; 2019. Available from: https://www.nap.edu/read/25354/chapter/1

16. Taichman $\mathbf{D}$, Bornstein SS, Laine C. Firearm Injury Prevention: AFFIRMing That Doctors Are in Our Lane. Ann Intern Med 2018;169(12):885-6.
17. Committing $\$ 2$ million to research gun-injury prevention [Internet]. 2018 [cited 2019 Dec 6];Available from: https://about.kaiserpermanente.org/ community-health/news/kaiser-permanente-commits-2-million-to-guninjury-prevention-res

18. Mass General Hospital launches new Center for Gun Violence Prevention - Massachusetts General Hospital, Boston, MA [Internet]. Massachusetts General Hospital. [cited 2019 Dec 6];Available from: https://www. massgeneral.org/news/press-release/mass-general-hospital-launchesnew-center-for-gun-violence-prevention

19. Tung EL, Johnson TA, O'Neal Y, Steenes AM, Caraballo G, Peek ME Experiences of Community Violence Among Adults with Chronic Conditions: Qualitative Findings from Chicago. J Gen Intern Med 2018;33(11):1913-20.

20. Hsu Y-T, Chang DC, Perez NP, et al. Civilian Firearm-related Injuries: How Often is a Tourniquet Beneficial? Ann Surg 2019;Available from: https://doi.org/10.1097/SLA.0000000000003622

21. Selker HP, Selker KM, Schwartz MD. Gun violence is a health crisis: physicians' responsibilities. J Gen Intern Med 2013;28(5):601-2.

22. Holt SR, Rosenbaum J, Ellman M, Doolittle B, Tobin DG. Physicians Should Play a Role in Ensuring Safe Firearm Ownership. J Gen Intern Med 2019;Available from: https://doi.org/10.1007/s11606-019-05034-

23. Hills-Evans K, Mitton J, Sacks CA. Stop Posturing and Start Problem Solving: A Call for Research to Prevent Gun Violence. AMA J Ethics 2018;20(1):77-83.

24. Betz ME, McCourt AD, Vernick JS, Ranney ML, Wintemute GJ. Firearms and Dementia. Ann Intern Med 2018;169(10):740.

25. Gondi S, Pomerantz AG, Sacks CA. Extreme Risk Protection Orders: An Opportunity to Improve Gun Violence Prevention Training. Acad Med 2019;94(11):1649-53.

26. Sacks CA. In memory of Daniel-reviving research to prevent gun violence. N Engl J Med 2015;372(9):800-1.

27. National Electronic Injury Surveillance System-All Injury Program | Healthy People 2020 [Internet]. [cited 2019 Sep 10];Available from: https://www.healthypeople.gov/2020/data-source/national-electronicinjury-surveillance-system-all-injury-program

28. CDC's National Violent Death Reporting System (NVDRS) [Internet]. [cited 2019 Sep 10];Available from: https://www.cdc.gov/violenceprevention/ pdf/NVDRS-factsheet508.pdf

29. Galea S, Branas CC, Flescher A, et al. Priorities in Recovering From a Lost Generation of Firearms Research. Am J Public Health 2018;108(7):858-60.

30. Teret SP, Wintemute GJ, Beilenson PL. The Firearm Fatality Reporting System. A proposal JAMA 1992;267(22):3073-4.

Publisher's Note: Springer Nature remains neutral with regard to jurisdictional claims in published maps and institutional affiliations. 